\title{
Education and technology used to improve the quality of life for people with diabetes mellitus type II
}

\section{Brooke Dudley \\ Brianne Heiland \\ Elizabeth Kohler-Rausch \\ Mark Kovic}

Midwestern University Occupational Therapy Program, Downers Grove, IL, USA
Correspondence: Brooke Dudley Midwestern University Occupational Therapy Program; 555 3I st Street, Downers Grove, IL, USA 605 I5

$\mathrm{Tel}+18013183014$

Email Bdudley84@midwestern.edu
This article was published in the following Dove Press journal:

Journal of Multidisciplinary Healthcare

5 March 2014

Number of times this article has been viewed

Background: The incidence of type II diabetes mellitus (DMT2) is expected to continue to rise. Current research has analyzed various tools, strategies, programs, barriers, and support in regards to the self-management of this condition. However, past researchers have yet to analyze the education process; including the adaptation of specific strategies in activities of daily living and roles, as well as the influence of health care providers in the integration of these strategies.

Objectives: The purpose of this qualitative case study was to identify the strengths and limitations of the current model of diabetes education in the United States and hypothesize how technology can impact quality of life.

Methods: Key informants on diabetes education were recruited from diabetes education centers through the American Association of Diabetes Educators. Semi-structured interviews were conducted with participants.

Results: Health care practitioners convey limited knowledge of DMT2. Individuals with DMT2 often have limited understanding of the implications of poor self-management. There appears to be no consistent standard of care for how to effectively incorporate self-management strategies. There is limited education for the use of technology in self-management. Diabetes educators describe that technology could be beneficial.

Conclusion: Findings suggest the importance of the role of care providers in emphasizing the implications of poor self-management strategies; that a multidisciplinary approach may enhance the education process; and a need for further developments in technology to address DMT2 self-management strategies.

Keywords: health promotion, quality of life, diabetes mellitus type 2, technology, health education

\section{Introduction}

\section{Background information}

Type II diabetes mellitus (DMT2) is a condition that occurs when the body is unable to secrete adequate amounts of insulin or when the insulin that is produced is unable to be used by the body due to insulin resistance. Genetic factors have an impact on an individual's risk of developing DMT2; however, previous research has found that environmental factors such as obesity, physical inactivity, high fat, low fiber diets, smoking, and low birth weight can also be critical components leading to the development of DMT2. ${ }^{1}$ Common symptoms of DMT2 include frequent urination, excessive thirst, constant hunger, lack of energy, weight loss or weight gain, and blurred vision. ${ }^{2}$

There are various secondary complications that can occur as a result of DMT2. Individuals diagnosed with DMT2 are at an increased risk for developing 
cardiovascular conditions such as coronary heart disease, stroke, peripheral arterial disease, nephropathy, retinopathy, and cardiomyopathy. Due to a weakened immune system, individuals with DMT2 often experience slower recovery when they are faced with illness and injury. Sensory deficits are also a concern due to difficulty detecting the presence of wounds, especially on the feet. ${ }^{3}$ According to the American Diabetes Association, more than $60 \%$ of non-traumatic lower limb amputations occur in people with DMT2. ${ }^{3}$ In summary, the secondary complications from diabetes may lead to further confounding challenges for these individuals. Therefore, we know it is critical to manage the condition to prevent further complications.

Patients diagnosed with DMT2 may feel very overwhelmed due to the magnitude of the condition, the required lifestyle changes, and the fact that currently no cure exists for DMT2. DMT2 affected approximately 285 million people worldwide in 2010 and is on the rise in developing countries. It is predicted that 430 million people will be diagnosed by 2030 due to the western lifestyle of high energy diets and physical inactivity. ${ }^{4}$ With this in mind, it is becoming even more imperative that lifestyle factors are further addressed in order to avoid DMT2 becoming an even greater worldwide epidemic.

Once diagnosed with DMT2, the client should implement self-management strategies to prevent secondary complications and to maintain wellness. A self-management regime may include blood glucose monitoring, physical activity, coordinating appointments with a primary care provider, attending educational classes and support groups, tracking nutrition, etc. DMT2 health care professionals include: primary care practitioners, dietitians, podiatrists, ophthalmologists, diabetes educators, and psychologists. Resources and tools available include: cookbooks, glucose monitors, and web-based tools to track diet and exercise. ${ }^{3}$

In this article we will address the education process, the adaptation of strategies and tools into one's lifestyle, and the influence of the health care team through this study. Given the expected rise in the incidence of this condition, the possible fatal implications, and the complexity of establishing effective self-management routines, we examined the perceptions of diabetes educators. This was done in order to identify areas of need and potential solutions for the education process and adaptation of self-management strategies.

\section{Technology in health care}

Technology is rapidly expanding our ability to access information, and impacting our culture and how we live our daily lives. As such, health care professionals should consider how the use of technology might impact health care delivery. Researchers have begun to examine the effectiveness of technology in diabetes education; however, further research is warranted.

Glasgow et al implemented a web-based diabetes self-management program that addressed healthy eating behaviors, physical activity, and medication management. The researchers identified the worldwide web to be a useful medium, but there exists a need for a better connection between the health care team, patients, and the web-based program. The researchers determined that additional research needs to be completed before drawing conclusions. ${ }^{5}$

Other researchers considered the relationship between Diabetes TeleCare system and standard of care for people with diabetes living in rural South Carolina. Telehealth included interactive video conferencing, telephones, fax lines, and telehealth-enabled retinal cameras. The results showed statistically significant differences between the two groups related to glycated hemoglobin levels, but no difference in weight or circumferential measurements. ${ }^{6}$ Due to the implications for further research, we examined the use of technology in the current education process in order to understand its current use and potential for the future.

\section{Methods \\ Participants}

Members of our targeted population were adult key informants on DMT2. This study included three participants who were recruited through the American Association of Diabetes Educators (AADE) and the inclusion criteria included: adult key informants on diabetes. The exclusion criteria were as follows: individuals $<17$ years old, people who are not key informants on DMT2, and any individual who demonstrates an inability to comprehend the process of informed consent. The consent process included informing individuals of their right to withdraw from the study for any reason and at any time. Demographic information is as follows:

- Participant one: dietitian and certified diabetes educator (CDE) with 25 years of experience.

- Participant two: public health nutritionist and CDE with 5 years of experience.

- Participant three: AADE program coordinator and CDE with 12 years of experience.

\section{Procedure}

Participants completed an initial semi-structured interview, followed by member checking with the research team through 
telephone or video conferencing. Demographic information including job title, current and previous settings of employment, and years of experience was collected at the beginning of the first interview. Due to a lack of existing assessment tools related to the research topic, the research team created a list of questions to guide the interviews.

\section{Data analysis}

Researchers performed preliminary data analysis during the study alongside data gathering. This allowed the research team to identify patterns early on, and the questions that were provided during subsequent interviews were focused on these patterns. Each researcher coded the interviews individually. The researchers then met for a data analysis meeting for each interview in order to verify significant themes and conclusions. Axial coding was then conducted to identify and discuss significant findings from all three interviews. Finally, once themes had been identified, a follow-up interview was conducted in order to verify findings and ask follow up questions.

\section{Results}

Researchers identified four main themes: role of successful client, role of diabetes educator, supports and barriers to diabetes education, and technology potential (Table 1).

\section{Role of successful client}

Researchers identified characteristics of a successful client including: accountability, motivation for change, and active participation. Educators perceived education to be most effective when the clients demonstrate motivation for change. Educators emphasize the importance of client's active participation and accountability.

I find that it's very helpful for patients when I help them set goals, and then schedule another appointment right then and there, and say, "ok you're going to work on this for one week or two weeks and you're going to come back", so giving them those reporting tools and holding them accountable (participant \#2).

\section{Supports for diabetes education}

Educators acknowledged the following support for the education process: peer support, community resources, and structured curriculum.

The process is to make it not a lecture but to make it a discussion, engage other people to share their experiences and to learn from each other and not just you know the teacher so to speak ... I think that has really helped engage patients and it's helped just provide better quality education (participant \#3).

Peer support can be provided in a variety of ways, such as direct contact in a group setting or via technology through online support groups and blogs. A number of curriculums are available for use in the education programs.

If there isn't an exercise person there, someone who would do the teaching of the mechanics and movements, I would teach it because I am using a curriculum that specifically tells me what I'm supposed to be saying (participant \#1).

Educators also utilized other community resources, such as fitness centers, to enhance the education process.

\section{Barriers for diabetes education}

Barriers identified included: client perceptions, insurance policies, ineffective multidisciplinary approach, and communication. Participants acknowledged that health care practitioners tend to convey limited knowledge of DMT2 to their clients.

I think providers tend to blow it off more often than they should because people often have high blood sugars and they so often come in and are still high, and I think that if they don't get that feedback from their provider that says this is serious we need to make some changes and I think they interpret it as it's not that bad (participant \#3).

In addition to the barriers mentioned above, clients' own perceptions of DMT2 may negatively impact their self-management.

"I don't know if people realize how important some of those skills are to have" (participant \#2).

Participants recognized a need for increased communication and collaboration between health care professionals involved in DMT2 care. Participants also acknowledged the absence of exercise specialists, such as physical therapists and occupational therapists.

\section{Role of diabetes educator}

Participants acknowledged the following duties: ongoing support, coaching, collaboration, outreach, networking, and program development. The diabetes educators stressed the importance of individualized care. One-on-one care usually includes collaborative and coaching efforts including goal setting, action planning, and helping the client to understand 
Table I Significant themes and subthemes

\begin{tabular}{|c|c|}
\hline Themes & Illustrative quotes \\
\hline \multicolumn{2}{|l|}{ Role of client } \\
\hline Accountability & $\begin{array}{l}\text { I find that it's very helpful for patients when I help them set goals ... say 'ok you're going to work on this for } \\
\text { one week or two weeks and you're going to come back', so giving them those reporting tools and holding them } \\
\text { accountable (participant \#2). }\end{array}$ \\
\hline Motivation for change & $\begin{array}{l}\text { I think it's very individual and it just depends on what stage of change they are in, whether they are ready to } \\
\text { make changes or not, it depends on their level of motivation (participant \#3). }\end{array}$ \\
\hline Active participation & $\begin{array}{l}\text { Teaching people how to take care of themselves and how to empower themselves to take care of their diabetes } \\
\text { (participant \#2). }\end{array}$ \\
\hline \multicolumn{2}{|c|}{ Supports to the current diabetes education process } \\
\hline Peer support & $\begin{array}{l}\text { The process is to make it not a lecture but to make it a discussion, engage other people to share their } \\
\text { experiences and to learn from each other and not just you know the teacher so to speak ... I think that has } \\
\text { really helped engage patients and it's helped just provide better quality education (participant \#3). }\end{array}$ \\
\hline Structure curriculum & $\begin{array}{l}\text { When it comes to diabetes education, you can be credentialed to provide and you can look for credentialing } \\
\text { through the American Diabetes Association or the American Association for Diabetes Education (participant \#I). }\end{array}$ \\
\hline Community resources & $\begin{array}{l}\text { So when you think about health care related to diabetes, we have to push it to a level where there are more } \\
\text { people that are able to help us get the message out that diabetes controls the map ... People are doing diabetes } \\
\text { education in grocery stores. They go to the pharmacy, so people are doing diabetes education in pharmacies. } \\
\text { They go to church, so they are having diabetes education done in, church ... or whatever organization or } \\
\text { religious organization you may be a part of (participant \#I). }\end{array}$ \\
\hline \multicolumn{2}{|c|}{ Barriers to the current diabetes education process } \\
\hline Client perceptions & I think people feel that if they are not doing well they don't want to get reprimanded (participant \#3). \\
\hline Insurance & $\begin{array}{l}\text { Even though individualized care is ideal, it is difficult to provide due to insurance limitations and the limited } \\
\text { number of diabetes educators (participant } \mathrm{\# I} \text { ). }\end{array}$ \\
\hline $\begin{array}{l}\text { Ineffective transdisciplinary } \\
\text { approach }\end{array}$ & $\begin{array}{l}\text { We just haven't set up or incorporated a way to make that education more cohesive and planned out so that } \\
\text { we can include all these other disciplines (participant \#2). }\end{array}$ \\
\hline $\begin{array}{l}\text { Ineffective communication } \\
\text { between practitioner and client }\end{array}$ & $\begin{array}{l}\text { Her provider and her did not connect on the fact that she has a very serious disease that is going to kill her if } \\
\text { she keeps her AIC up that high (participant \#3). }\end{array}$ \\
\hline \multicolumn{2}{|l|}{ Role of diabetes educator } \\
\hline Coach & $\begin{array}{l}\text { The things that work are, if you ask somebody to check blood sugar, you need to follow up with them and } \\
\text { show them, and explain to them exactly how, like, ok you had a high blood sugar, what have you eaten, had } \\
\text { you exercised, what are some of the factors that increase blood sugar or decrease it and actually look at their } \\
\text { information, and help them to understand it so that they're not just collecting information. So the things that } \\
\text { work are things that people can really understand and apply to their own life (participant \#2). }\end{array}$ \\
\hline \multicolumn{2}{|l|}{ Collaboration } \\
\hline Outreach and network & $\begin{array}{l}\text {... figuring out who the kind of like movers and shakers are in the community and getting them to kind of be on } \\
\text { your side and buy into "hey we're doing a cooking class, can you let all of your employees know, or all of your } \\
\text { patients know," or whatever (participant \#2). }\end{array}$ \\
\hline Program development & $\begin{array}{l}\text { The goal of any diabetes educator who is doing a good job is to use a curriculum that has been tested and } \\
\text { scientifically proven (participant \#I). }\end{array}$ \\
\hline Ongoing support & $\begin{array}{l}\text { It's really challenging to get people to come back and we need to focus on that and figure out better ways to } \\
\text { provide that support, technology being one (participant \#3). }\end{array}$ \\
\hline Technology & $\begin{array}{l}\text { Cause, I know personally, me, I do schedule my exercise, and I put it into my [electronic] calendar. So every } \\
\text { week, when I have my little to-do list, my exercise is on my to-do list (participant \#3). }\end{array}$ \\
\hline
\end{tabular}

DMT2 and how specific strategies can be applied to the client's own life.

Along with individualized care, effective diabetes education also requires ongoing support.

Mostly because it takes a couple of times, at least what I've found. They hear the diabetic nurse say it once, and it kind of makes sense how diabetes works and what's going on. And then hearing it a second time or even a third time it just starts to get more and more clear. So I always explain it again, just because they generally need that (participant $\# 2$ ).

\section{Technology}

The participants verified incorporating technology into diabetes education and self-management.

The main way that I use technology is teaching people how to use some of these apps ... that are available just for self monitoring, food intake, and physical activity (participant \#2).

Technology may be utilized in a number of ways, such as smartphone applications, computer programs, online 
support groups, or text messaging; however, not all clients utilize technology.

There is a difference between those that are skyping and those that are just getting a text message from a health coach. And I personally think face-to-face is much more effective (participant \#1).

Conversely, this same participant acknowledged future potential:

So I know technology advancements are definitely going to help us much more (participant \#1).

The results indicate mixed views on the current use of technology. The participants emphasized the importance of simplifying technology in order to allow more individuals to benefit from its use.

\section{Discussion}

The results of this study highlight current barriers and support in diabetes education, as well as the implications for health care professionals working with clients with DMT2. In addition, potential uses of technology may facilitate the needed ongoing support and individualized care. Clients with DMT2 must reinvent their lifestyle, which should incorporate self-management strategies. The diabetes educator facilitates this process. The results also highlight certain factors and characteristics of the educator and client, which may lead to this lifestyle change.

Based on this current study, we conclude that the first step toward integrating self-management strategies into daily life is to identify motivational factors for change. In order to effectively alter one's lifestyle and enhance quality of life, clinicians should hold their clients accountable for diabetes management strategies. Success, however, lies with the client, who plays a crucial role in how to best incorporate these lifestyle changes by actively participating in this process.

The support identified in this study evolves the education process into more than a didactic curriculum. Selfmanagement involves gaining knowledge and insight into strategies such as blood glucose monitoring, tracking nutrition, and managing medication. ${ }^{3}$ Anthony et al speculate that if patients gained increased knowledge of the damage caused by elevated blood pressure, then they would be more apt to follow a treatment regime. ${ }^{7}$ Currently, educators not only need to convey knowledge, but also build client skills through their curriculum. One method may be the use of collaborative goal setting. In addition, supports must be considered for the clients' social and physical environment. Based on the results of this study, peer support often facilitates sharing of ideas, concerns, and tools, which may better integrate self-management strategies. Korkiakangas et al found that time management skills and social support may positively influence exercise participation. ${ }^{8}$

Health care practitioners should be prepared to assist those who have limited knowledge of community resources, limited social interaction, or low socioeconomic status.

The impact of specific barriers affects the clients' abilities to integrate and maintain self-management strategies and the educator's ability to support the education process. Past studies have examined client perceptions on DMT2 management strategies. Huebschmann et al examined client perceptions and discovered that a fear of failing limited people with DMT2 the ability to incorporate exercise into their lifestyle. ${ }^{9}$ The results of the present study also showed how health care practitioners might negatively influence perceptions of clients. According to Nam et al, primary care practitioners' attitudes toward diabetes management may be more impactful than actual knowledge of the condition. ${ }^{10}$ Reinforcing concern over a client's quality of life and DMT2 management strategies may address certain perceptions that are negatively impacting an individual's ability to live a healthy lifestyle.

In order to further ongoing support, clinicians involved in treating individuals with DMT2 should consider communicating more directly with one another. By integrating a multidisciplinary approach, the education process may be enhanced due to the limited number of educators compared to the large client population. Multidisciplinary communication may also promote better care due to the various areas of expertise. Regardless of the team composition, Rodriguez suggests that better relationships between clients and the health care practitioner contribute to increased participation in diabetes self-management. ${ }^{11}$ Insurance often dictates the type of services a client receives, therefore a multidisciplinary approach may reinforce lifestyle change and address barriers to self-management.

Educators' expectations of their role and the clients may influence the education process and the success of the clients. Not only are the educators working directly with clients, but they should connect to surrounding community and educational organizations. Educators should develop programs that not only provide individualized care, but also group-based care. Enza et al recommend that intervention features that impact the broader community may be more beneficial than the more traditional strategies such as didactic curriculums. ${ }^{12}$ Program development is a continuous process, as educators 




Figure I Interactive components of diabetes education.

receive new clients and research continues to provide further information.

The complexities of the individual and DMT2 may not fully be addressed by one health care practitioner alone. Clients not only learn from the educator, but also peers, other health professionals, and their own experiences. The difficulty in creating a unified team lies within the barriers to the education system. We see promise in the use of technology in bridging the gaps between the client, the health care team, and the educator (Figure 1).

Clinicians are becoming more aware of the benefits of technology in health promotion, prevention, and intervention. Organizations such as the American Occupational Therapy Association provide practitioners with resources on available smartphone apps and technological tools. ${ }^{13}$ The World Health Organization acknowledges the potential of technology development to support health care services. ${ }^{14} \mathrm{We}$ recommend technology development be approached from a holistic view considering the health care team, client population, and factors related to DMT2. With the correct development, technology may assist in providing ongoing support, providing individualized care, connecting health care practitioners, and be engaging and meaningful. The client should use technology that reflects the principles taught in the education process, and use it to connect with the health care team. Rodriguez suggests that the individual client is central to every decision, therefore it is important to keep this in mind when recommending tools and technology. ${ }^{11}$ Since participants in this study were unable to identify specific technological tools that were the most effective at meeting self-management strategies, we can conclude that such a tool still needs to be developed.

\section{Limitations}

The most significant limitation of this study is the limited number of participants. All participants were associated with the AADE, which may have restricted the results of this study. Other educational programs and affiliations should be considered to expand on these results. Further research is needed in order to evaluate specific technological tools for supporting the education curriculum and self-management strategies. Implications for providing ongoing support and individualized care need to be further analyzed in order to improve the current standard of care.

\section{Conclusion}

Based on the results of this study, we conclude that the client is the most critical person in the diabetes education process; he/she must want to change. However, the way the health care team works together and implements technology and education greatly affects the client's success. We propose that additional professionals, such as occupational therapists, 
exercise physiologists, and technology experts should be included in the diabetes education process for a more wellrounded, successful program.

\section{Disclosure}

The authors declare no conflicts of interest in this work.

\section{References}

1. Skyler JS, editor. Atlas of Diabetes. 2nd ed. Philadelphia: Lippincott Williams \& Wilkins; 2002.

2. Beaser RS, Campbell AP. The Joslin Guide to Diabetes. 2nd ed. New York: Fireside; 2005.

3. Diabetes.org [homepage on the Internet]. Alexandria, VA. The American Diabetes Association; c1995-2013. Available from: http://www.diabetes. org/. Accessed October 1, 2012.

4. Tahrani A, Bailey C, Prato S, Barnett A. Management of type 2 diabetes: new and future developments in treatment. The Lancet. 2011; 378(9786):182-197.

5. Glasgow RE, Kurz D, Dickman JM, Osuna D, Strycker L, King DK. Linking internet-based diabetes self-management to primary care: lessons learned and implications for research translation and practice implementation. Transl Behav Med. 2012;2(3):313-321.

6. Davis RM, Hitch AD, Salaam MM, Herman WH, Zimmer-Galler IE, Mayer-Davis EJ. TeleHealth improves diabetes self-management in an underserved community: diabetes TeleCare. Diabetes Care. 2010;33(8):1712-1717.
7. Anthony H, Valinsky L, Inbar Z, Gabriel C, Varda S. Perceptions of hypertension treatment among patients with and without diabetes. $B M C$ Fam Pract. 2012;13:24.

8. Korkiakangas EE, Alahuhta MA, Husman PM, Keinänen-Kiukaanniemi S, Taanila AM, Laitinen JH. Motivators and barriers to exercise among adults with a high risk of type 2 diabetes - a qualitative study. Scand J Caring Sci. 2011;25(1):62-69.

9. Huebschmann AG, Crane LA, Belansky ES, Scarbro S, Marshall JA, Regensteiner JG. Fear of injury with physical activity is greater in adults with diabetes than in adults without diabetes. Diabetes Care. 2011;34(8):1717-1722.

10. Nam S, Chesla C, Stotts NA, Kroon L, Janson SL. Barriers to diabetes management: patient and provider factors. Diabetes Res Clin Pract. 2011;93(1):1-9.

11. Rodriguez KM. Intrinsic and extrinsic factors affecting patient engagement in diabetes self-management: perspectives of a certified diabetes educator. Clin Ther. 2013;35(2):170-178.

12. Enza G, Vivian C, Lisa M, Souraya S. A systematic literature review of diabetes self-management education features to improve diabetes education in women of black african/caribbean and hispanic/latin american ethnicity. Patient Educ Couns. 2013;92:235-245.

13. Yamkovenko S [web site on the Internet]. American Occupational Therapy Association; c2012. Available from: http://www.aota.org/ Practitioners/Resources/Apps.aspx/. Accessed October 23, 2012.

14. World Health Organization. Telemedicine: Opportunities and Developments in Member States. Geneva: WHO Press; 2011.
Journal of Multidisciplinary Healthcare

\section{Publish your work in this journal}

The Journal of Multidisciplinary Healthcare is an international, peerreviewed open-access journal that aims to represent and publish research in healthcare areas delivered by practitioners of different disciplines. This includes studies and reviews conducted by multidisciplinary teams as well as research which evaluates the results or conduct of such teams or health-

\section{Dovepress}

care processes in general. The journal covers a wide range of areas and welcomes submission from practitioners at all levels, from all over the world. The manuscript management system is completely online and includes a very quick and fair peer-review system. Visit http://www.dovepress. com/testimonials.php to read real quotes from published authors. 